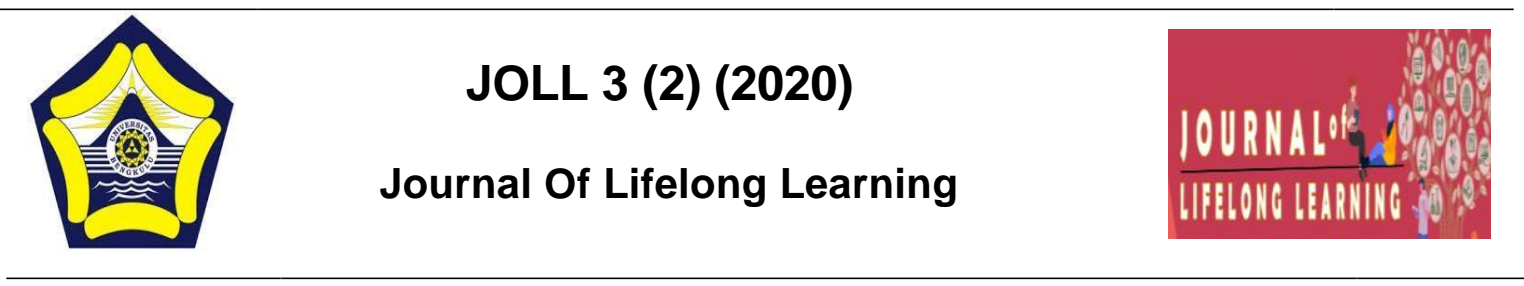

\title{
PELAKSANAAN PELATIHAN BAHASA INGGRIS DALAM PROGRAM PENDIDIKAN KECAKAPAN KERJA (PKK)
}

\author{
Resti Anggraini ${ }^{1}$, Ilham Abdullah ${ }^{2}$, Ririn Gusti ${ }^{3}$ \\ ${ }^{1}$ Resti Anggraini, Universitas Bengkulu, Indonesia, anggrainiresti1303@gmail.com \\ ${ }^{2}$ Ilham Abdullah, Universitas Bengkulu, Indonesia, ilhamabdullah@unib.ac.id \\ ${ }^{3}$ Ririn Gusti, Universitas Bengkulu, Indonesia, riringusti@unib.ac.id
}

\begin{abstract}
The purpose of this study is to determine the implementation of English competency tests in work skills education programs at LKP Cororado English Course Bengkulu City. This research is a qualitative research with as many as three research subjects and data collection techniques using interview, observation and documentation techniques. While data analysis techniques include data reduction, data presentation, and drawing conclusions. Checking the validity of the data using triangulation ranging from time triangulation, subject triangulation and technique triangulation. The results showed that the implementation of the competency test went well and in accordance with existing procedures, had adequate supporting facilities and facilities. However, the number of competency test participants who get incompetent results is due to several factors, namely the training carried out does not refer to graduate competency standards, design of learning implementation and syllabus. The training method only studies examples of existing problems. In addition, the training schedule is too tight and does not reach the minimum number of training hours, which is 144 hours.
\end{abstract}

Keywords: Implementation, Competency Test, English 


\section{PENDAHULUAN}

Pada Undang-undang No. 20 Tahun 2003 tentang Sistem Pendidikan Nasional pasal 1 ayat 12 dijelaskan bahwa "Pendidikan nonformal adalah jalur pendidikan di luar pendidikan formal yang dapat dilaksanakan secara terstruktur dan berjenjang". Lebih lanjut lagi dijelaskan pada pasal 26 ayat 3 , bentuk pendidikan nonformal meliputi pendidikan kecakapan hidup, pendidikan usia dini, pendidikan kepemudaan, pendidikan pemberdayaan perempuan, pendidikan keaksaraan, pendidikan keterampilan dan pelatihan kerja, pendidikan kesetaraan, serta pendidikan lain yang ditujukan untuk mengembangkan kemampuan peserta didik.

Dalam hal ini pendidikan nonformal memberikan pendidikan yang dengan sengaja dirancang untuk membekali peserta didiknya dengan keterampilan atau kecakapan hidup (life skill)."

Menurut Asmani (2009:37) "Pendidikan Kecakapan Hidup (life skill) adalah pendidikan kemampuan, kesanggupan, dan keterampilan seseorang untuk menjalankan hidupnya."

Menurut Ratna Susanti (2002:87) menjelaskan bahwa "Seiring berkembangnya ilmu pengetahuan dan teknologi di dalam era yang semakin mengglobal ini, tak dapat dipungiri bahwa kemampuan dalam berbahasa asing, terutama bahasa Inggris sangat penting. Namun demikian tidak sedikit siswa yang prestasi belajar bahasa inggrisnya belum memadai."

Lebih lanjut, Menurut Nur Hidayanto (2013:61) "Tantangan dunia global yang sarat dengan muatan persaingan mengisyaratkan bahwa seseorang yang ingin berhasil memerangi dunia nyata perlu memiliki kemahiran yang diakui oleh dunia global, yaitu bahasa Inggris sehingga dapat dengan mudah mencari kerja di Indonesia maupun Mancanegara"

Menurut Muhammad Hilman (2018:155) "Kebutuhan Masyarakat akan pentingnya bahasa Inggris tersebut mendorong masyarakat untuk memenuhi kebutuhannya dalam mempertajam kemampuan (skill) dalam berbahasa Inggris."

Untuk mewujudkan tujuan tersebut pemerintah membuat sebuah program Pendidikan Kecakapan Kerja (PKK) yang menurut PERDIRJEN PAUD DAN DIKMAS NO 20 TAHUN 2019 program pendidikan kecakapan kerja adalah program layanan pendidikan dan pelatihan berorientasi pada

pengembangan keterampilan kerja yang diberikan kepada peserta didik agar memiliki kompetensi dibidang keterampilan tertentu yang sesuai dengan peluang kerja dan dapat diselenggarakan oleh lembaga yang memiliki NPSN nonformal dan lembaga yang tidak memiliki NPSN nonformal.

Lembaga penyelenggara program PKK yang memiliki NPSN nonformal, yaitu LKP, PKBM dan SKB.

Di Bengkulu sendiri yang sering menyelenggarakan program pendidikan kecakapan kerja adalah Lembaga Kursus dan Pelatihan (LKP). Ada banyak bidang pendidikan yang ada pada pendidikan 
kecakapan kerja, salah satunya adalah pendidikan kecakapan kerja bahasa inggris. Salah satu LKP di Bengkulu yang menyelenggarakan program PKK Bahasa Inggris selama tiga tahun terakhir, antara lain : LKP Colorado, LKP Essential, LKP Little Bee dan LKP Sinar Anak Bangsa. Sedangkan Tempat Uji Kompetensi Bahasa Inggris pada program PKK di Provinsi Bengkulu ini adalah LKP Colorado.

Berdasarkan wawancara pada tanggal 25 Desember 2019 bersama ibu Dian selaku sekretaris LKP Colorado didapatkan informasi bentuk pelaksanaan Program Pendidikan Kecakapan Kerja berbentuk tatap muka menggunakan silabus yang telah ditentukan dengan alokasi waktu 200 jam pelajaran. Sarana pendukung pelaksanaan test tertulis, yaitu : Compact Disk (CD) audio dari Lembaga Sertifikasi Kompetensi (LSK), Booklet tes dari LSK, lembar jawaban dari LSK, Compact Disk (CD) player dari Tempat Uji Kompetensi (TUK) dan ruangan beserta kursinya dari TUK. Sedangkan untuk sarana ujian oral, yaitu meja dan kursi untuk peserta dan penguji dalam melaksanakan test oral (wawancara). Bentuk pelaksanaan ujian Program Pendidikan Kecakapan Kerja bahasa inggris hampir sama dengan test toefl hanya saja pada ujian kompetensi ini menggunakan test wawancara dan tertulis. Materi ujian terdiri dari dua bentuk, yaitu tertulis yang mencakup listening, reading, writing dan oral test, yaitu speaking.
Untuk mengukur kemampuan peserta didik dalam mengikuti program pendidikan kecakapan kerja dibidang Bahasa Inggris maka peserta didik wajib mengikuti uji kompetensi yang di selenggarakan oleh Lembaga Sertifikasi Kompetensi Bahasa Inggris (LSK-BIG), dimana untuk di Provinsi Bengkulu lembaga yang ditunjuk oleh LSK-BIG sebagai Tempat Uji Kompetensi (TUK) Uji Kompetensi Bahasa Inggris adalah LKP Colorado.

Menurut data Lembaga Sertifikasi Kompetensi Bahasa Inggris (LSK-BIG) yang didapat saat observasi ke LKP Colorado pada tanggal 25 Desember 2019, selama tiga tahun terakhir peserta yang mengikuti uji kompetensi Bahasa Inggris yang dinyatakan berkompeten tidak pernah mencapai $50 \%$ dari jumlah peserta yang mengikuti ujian

dapat diketahui bahwa selama tiga tahun terakhir, lembaga yang menyelenggarakan program Pendidikan Kecakapan Kerja (PKK) adalah Colorado English Course, Essential English Center, Sinar Bangsa dan Little Bee. Dari lembaga-lembaga yang menyelenggarakan program Pendidikan Kecakapan Kerja, tidak ada lembaga yang memiliki peserta berkompeten diatas $50 \%$.

\section{METODE}

Penelitian ini menggunakan metode penelitian kualitatif, yaitu metode yang bersifat mengamati kasus yang didasarkan pada pendekatan post positivisme. Menurut Sugiyono (2014:8) metode penlitian kulaitatif yaitu : 
metode penelitian kualitatif adalah metode penelitian yang berlandaskan pada falsafat postpositivisme, digunakan untuk meneliti pada kondisi objek yang alamiah, dimana peneliti adalah instrumen kunci, teknik pengumpulan data dilakukan secara tri anggulasi, analisis data bersifat induktif/kualitatif, dan hasil penelitian lebih menekankan makna daripada generalisasi.

Dalam melakukan penelitian dan menggali data dilapangan peneliti menggunakan tiga teknik pengumpulan data yaitu wawancara, observasi dan dokumentasi dengan menempatkan peneliti sebagai instrument kunci.

Menurut Gay dan Airasian (dalam Emzir, 2014:37) 'Observasi, wawancara, dokumen pribadi dan resmi, foto, rekaman, gambar, dan percakapan informal semua merupakan sumber data kualitatif".

Partisipan pada penelitian ini yaitu Ibu Tanti dari lembaga Little Bee yang merupakan lembaga penyelenggara program PKK, Assyifa Rahma Dwi Phitaloka yang merupakan peserta program PKK, dan ibu Dian Eka Gustini dari lembaga Colorado English Course yang merupakan penyelenggara/ Tempat Uji Kompetensi (TUK).

Dalam menguji validitas data peneliti menggunakan teknik trianggulasi yaitu trianggulasi waktu, trianggulasi subjek dan trianggulasi teknik. Menurut Sugiyono (2015: 83) mengatakan bahwa triangulasi adalah teknik pengumpulan data yang bersifat menggabungkan dari berbagai teknik pengumpulan data dan sumber data yang telah ada. Uji keabsahan data pada penelitian kualitatif dengan menggunakan triangulasi akan lebih meningkatkan kekuatan data apabila dibandingkan dengan satu pendekatan. Dalam penelitian ini, peneliti menggunakan teknik keabsahan data dengan triangulasi teknik.

Sedangkan dalam melakukan analisis data peneliti menggunakan model miles \& Huberman, yaitu dimulai dari mereduksi data, melakukan penyajian data, serta melakukan verifikasi dan pengambilan keputusan.

\section{HASIL DAN PEMBAHASAN}

Penelitian dilakukan di LKP Little Bee yang merupakan lembaga penyelenggara program PKK bahasa Inggris. Pada pelatihan PKK bahasa Inggris yang dilaksanakan di LKP Little Bee, terdapat perbedaan antara silabus pembelajaran yang diberikan yaitu silabus English For Tourism dan RPP yang digunakan adalah General English sedangkan seharusnya materi pelatihan yang sesuai dengan uji kompetensi adalah Survival English, kemudian dari absensi pelatihan hanya dilakukan selama dua minggu dari hari Senin hingga Sabtu dengan waktu belajar 8 jam per hari terdiri dari $30 \%$ teori dan $70 \%$ praktek dengan materi pelatihan mempelajari empat skill Bahasa Inggris, mempelajari modul dan buku. Selain itu, dari 40 peserta yang terdaftar sebagai peserta uji kompetensi hanya sebagian 
yang mengikuti pelatihan PKK dengan tutor atau instruktur pada pelatihan yaitu Wahyudi Badri, S.Pd dan Tri Tanti, S.Pd.

Menurut Edwin B. Flippo (dalam kamil, 2012:03) "Pelatihan adalah tindakan meningkatkan pengetahuan dan keterampilan seorang pegawai untuk melaksanakan perkerjaan tertentu."

Dari pendapat diatas, peneliti menyimpulkan bahwa pelatihan merupakan upaya untuk meningkatkan kapasitas pengetahuan maupun keterampilan seseorang. Dalam hal ini, pelatihan yang dilakukan adalah pelatihan Pendidikan Kecakapan Kerja (PKK).

Menurut PERDIRJEN PAUD dan DIKMAS No. 20 tahun 2019 tentang Petunjuk Teknis Bantuan Pemerintah Program Pendidikan Kecakapan Kerja (PKK) menyatakan bahwa Pendidikan Kecakapan Kerja (PKK) adalah program layanan pendidikan dan pelatihan berorientasi pada pengembangan keterampilan kerja yang diberikan kepada peserta didik agar memiliki kompetensi dibidang keterampilan tertentu yang sesuai dengan peluang kerja.

Dari pendapat di atas, peneliti menyimpulkan bahwa, PKK merupakan layanan pendidikan yang disediakan pemerintah untuk mengembangkan skill atau keterampilan kerja agar memiliki keterampilan dibidangnya. Dalam pelaksanaan PKK perlu adanya perencanaan yang matang sehingga pelatihan dapat berjalan sesuai yang diharapkan.
Menurut Beni Susetya (2017:134) "Perencanaan pembelajaran merupakan langkah yang sangat penting sebelum pelaksanaan pembelajaran. Perencanaan yang matang diperlukan supaya pelaksanaan pembelajaran berjalan secara efektif."

Lebih lanjut dijelaskan Beni Susetya (2017:134) "perencanaan pembelajaran dituangkan dalam rencana pembelajaran yang memuat KI, KD, Idikator yang dicapai, materi yang akan dipelajari, langkah pembelajaran, media pembelajaran, dan sumber belajar serta penilaian."

Dari pendapat diatas, peneliti menyimpulkan bahwa dalam pembelajaran perlu adanya perencanaan dalam pelaksanaan baik tentang kompetensi dan indikator yang ingin dicapai, materi yang akan diperlajari, hingga media dan sumber pembelajaran harus direncanakan dengan matang.

Menurut Penyelenggara Uji Kompetensi Bahasa Inggris (UK-BIG) durasi waktu per program adalah 144 jam dengan distribusi waktu $30 \%$ teori dan $70 \%$ praktek terintegrasi.

Dari pendapat diatas, peneliti menyimpulkan bahwa selain adanya perencanaan yang matang dalam pelatihan, durasi waktu juga harus memenuhi kriteria yang ditetapkan agar mendapatkan hasil yang maksimal.

\section{KESIMPULAN}

Pelatihan program Pendidikan Kecakapan Kerja (PKK) Bahasa Inggris di lembaga peserta Uji Kompensi yaitu LKP Little Bee tidak berjalan dengan efektif karena tidak ada silabus dan RPP 
khusus yang digunakan dalam pelatihan atau RPP dan silabus yang digunakan berbeda dengan materi yang di ujikan.

Selain itu, Pelatihan hanya mempelajari materi-materi yang akan diujikan dan pelaksanaan pelatihan delapan jam sehari selama dua minggu dan pembelajaran tidak sampai 144 jam.

\section{REFERENSI}

Asmani. Dan Ma'mur Jamal. (2009) Manajemen Strategis Pendidikan Anak Usia Dini. Yogyakarta: Diva Pers.

Emzir. (2014). Metodologi Penelitian Kualitatif (Analisis Data). Jakarta : Rajawali Pers.

Hidayanto, Nur. (2013) Analisis Hasil Uji Kompetensi Pembelajaran Bahasa Inggris Dengan Model Logistik. Jurnal Kependidikan. 43(1) Hlm 6168.Hilman, Muhammad. (2018) Pengelolaan Program Kursus Bahasa Inggris pada Lembaga Kursus English Café Yogyakarta. Jurnal Pendidikan Luar Sekolah. 8 (2) hlm. 154-163.

Kamil, Mustofa. (2012). Model Pendidikan dan Pelatihan (Konsep dan Aplikasi). Bandung: Alfabeta

Peraturan Direktorat Jendral Pendidikan Anak Usia Dini dan Pendidikan Masyarakat No 20 tahun 2019 tentang Teknis Bantuan Pendidikan Kecakapan Kerja

Penyelenggara Uji Kompetensi Bahasa Inggris (UK-BIG).

Susetya, Beni. (2017) Meningkatkan Kemampuan Guru Dalam Menyusun Silabus dan RPP Melalui Supervisi Akademik di SDN Gambiran
Yogyakarta Tahun 2016. Jurnal Taman Cendikia. 1(2) hlm134-141

Sugiyono. (2014). Metode Penelitian Kuantitatif, Kualitatif, dan R \& D. Bandung: Alfabeta.

Sugiyono. (2015). Memahami Penelitian Kualitatif. Bandung: Alfabeta.

Susanti, Ratna. (2002). Penguasaan Kosa Kata dan Kemampuan Membaca Bahasa Inggris. Jurnal Pendidikan Penabur. 1 (1) hlm. 87-93. 